\title{
Limites e avanços do Programa Minha Casa Minha Vida (PMCMV): o caso do Conjunto Habitacional Jardim Europa em Fazenda Rio Grande
}

\author{
Corina Alessandra Bezerra Carril Ribeiro ${ }^{1}$ \\ Maria Tarcisa da Silva Bega ${ }^{2}$
}

\section{RESUMO}

Desde 2003, com a criação do Ministério das Cidades, o Brasil tem se destacado pela implantação de Políticas Públicas habitacionais como o Programa de Aceleração do Crescimento (PAC) criado em 2007 e o Programa Minha Casa Minha Vida (PMCMV), de 2009, que contaram com grande divulgação na mídia. Segundo o governo federal o PMCMV é a maior iniciativa de acesso à casa própria já criada no Brasil (Ministério das Cidades, 2016, p.22). O PMCMV apresenta avanços significativos como Política Pública quanto ao acesso à moradia para milhares de famílias de baixa renda, entretanto, houve a ocorrência de erros na execução dos projetos; qualidade do material construtivo e localização dos conjuntos, os quais demonstraram a necessidade de aperfeiçoamento e incorporação de melhorias. A pesquisa indica que o PMCMV além do acesso à casa própria representa um primeiro passo para o exercício da cidadania, mas, necessita de aperfeiçoamento contínuo e de Políticas Públicas integradas. O problema da habitação vai além do morar, sendo necessário que sejam disponibilizados aos beneficiários os serviços e equipamentos públicos necessários, tais como transporte, escola, emprego, saúde, acesso a serviços e áreas de lazer para que as famílias morem de forma adequada.

Palavras-chave: Programa Minha Casa Minha Vida; Fazenda Rio Grande; Conjunto Jardim Europa.

Possui graduação em Ciências Sociais pela Universidade de São Paulo, mestrado em Ciências Ambientais pela USP e Pós Doutorado em Sociologia pela Universidade Federal do Paraná (UFPR).

2 Doutora em Sociologia e professora do departamento de Sociologia e do Programa de Pós-graduação em Sociologia da UFPR. Coordena o Programa de Desenvolvimento Urbano e Regional (PDUR). 
A globalização possibilitou uma grande revolução nas comunicações aproximando as pessoas e facilitando os processos comunicativos. Entretanto, tem-se percebido que os aspectos econômicos em nível mundial têm afetado e piorado as condições de vida de milhares de pessoas que estão excluídas deste modelo de sociedade. Nas cidades, o cenário é desolador: concentração da pobreza e aumento da violência, do desemprego, crescimento do mercado informal, pela terceirização, degradação ambiental, exclusão social, segregação espacial e baixa expectativa de melhoria de vida.

No Brasil e no âmbito mundial, em pleno século XXI ainda se convivem com grandes desigualdades sociais, de renda, políticas, de gênero, entre outros problemas. Dentre outras razões, há a opção de governos em priorizar a lógica do capital internacional que reproduzem a concentração de renda e poder, além do histórico de práticas corruptas e má gestão administrativa do Estado.

Essa desigualdade está evidente nas cidades, na forma pela qual as populações pobres ocupam os espaços para fins de moradia e constroem seu cotidiano: o morar longe do trabalho, a ausência de espaços de lazer em seus bairros, os postos de saúde lotados, a baixa escolaridade, e a renda familiar insuficiente representam um perfil quase homogêneo das dificuldades encontradas pelos moradores dos inúmeros espaços de exclusão brasileiros (periferias ${ }^{3}$ ) somado à falta de perspectivas de melhores condições de vida. O que advém do fato de as Políticas Públicas contribuírem pouco para a transformação dessa situação.

\footnotetext{
3 Visto a heterogeneidade em que se encontram as regiões periféricas no Brasil, por vezes representam espaços de exclusão, por outros, são representadas pelo fenômeno dos condomínios fechados de alto padrão, ver o caso de Alphaville em Barueri/SP.
} 


\section{O Programa Minha Casa Minha Vida (PMCMV)}

Para potencializar o acesso das famílias ao mercado habitacional criou-se em 2009 o Programa Minha Casa Minha Vida (PMCMV) pelo governo federal, com recursos do Fundo de Arrendamento Residencial, que propõe acesso ao mercado habitacional para famílias que recebem até 10 salários mínimos e por outro lado, reaquece o ramo da construção protegendo-o da crise econômica internacional.

Segundo a Caixa Econômica Federal, o PMCMV a partir de parcerias com estados, município, empresas e entidades sem fins lucrativos, consiste em aquisição de terreno e construção ou requalificação de imóveis contratados que depois de concluídos são alienados às famílias que possuem renda familiar mensal de até R\$1.60o,oo. As famílias a serem beneficiadas pelo Programa são indicadas e selecionadas pelo município ou Governo do Estado/Distrito Federal.

Para o representante da Companhia de habitação popular de Curitiba (COHAB-CT), um dos atrativos do programa é o subsídio dado às famílias que pagarão prestações baixas, cerca de $10 \%$ da renda familiar. Uma das críticas que se faz ao programa é que o promotor do empreendimento acaba sendo o setor privado, pois os estados e municípios ficam responsáveis em organizar outras atividades tais como a demanda; facilitar a produção, através da desoneração tributária e flexibilização da legislação urbanística e cessão de terrenos públicos. "Neste sentido, cabe ao mercado à promoção dos empreendimentos imobiliários elaborados de acordo com as exigências técnicas mínimas do PMCMV, principalmente no que se refere ao cálculo do valor da unidade habitacional, de forma a se enquadrar no perfil financiado e, ao mesmo tempo, garantir maior taxa de lucro possível em seus projetos” (CARDOSO, 2011, p.6). 


\section{Breve histórico do Município de Fazenda Rio Grande}

O município de Fazenda Rio Grande, lócus de nossa pesquisa, foi escolhido por ser uma cidade jovem e periférica, resultado do desmembramento de Mandirituba e criada em 1993, com grandes taxas de crescimento populacional e por localizar-se próxima de Curitiba, distando cerca de 30 km. Segundo estimativa do IBGE (2017) a cidade atingiu cerca de 95.225 habitantes (entre população rural e urbana), tendo tido acréscimo populacional de 13.550 pessoas em sete anos em relação à 2010, pelo fato de dispor de terrenos mais baratos, e ambientalmente frágeis, em relação ao alto custo da habitação em Curitiba, representando nas últimas décadas a alternativa de moradia popular para muitas famílias de baixa renda. Essa realidade pode ser expressa pelo forte crescimento populacional do município em relação à Curitiba ${ }^{4}$.

No Plano Diretor do município (2006) a imagem de cidade-dormitório está presente, e reforça o papel que essa cidade representa, ao lado de outras vizinhas, (tais como Colombo, Campina Grande do Sul, Almirante Tamandaré, entre outras) de uma cidade que dispõe de grande oferta de mão de obra trabalhadora que trabalha em Curitiba, lugar onde se localizam os empregos e serviços.

Nos últimos anos o município de Fazenda Rio Grande tem tentado mudar essa imagem ${ }^{5}$, atraindo grandes empresas para se instalarem na cidade e ofertarem empregos. Com a chegada da Tirol, do setor alimentício e que montará seu Centro de

\footnotetext{
4 Segundo dados do Ipardes de 2010, a taxa de crescimento geométrico populacional de Fazenda Rio Grande era de 2,65, enquanto a de Curitiba no mesmo período era de 0,99 .

5 Ver atualização do Plano Diretor da Cidade que pretende mudar a visão de cidade dormitório no Capítulo III DOS OBJETIVOS GERAIS Art. 16 - São objetivos gerais do Plano Diretor de Fazenda Rio Grande; I - transformar a característica de município-dormitório, para Município com desenvolvimento econômico e social sustentado
} 
Distribuição; Romo Patents, termoelétrica que usa pneu com base da energia; Pedro Rocha e Andal, do setor metal mecânico e que produzem materiais para Logística; e a Terrazzo, do setor de construção civil, estão previstas as chegadas de mais de 50 empresas para atender toda a demanda (Site da Prefeitura de Fazenda Rio Grande, 2015).

Apesar do esforço da Prefeitura em tentar reverter o quadro de cidade dormitório destaca-se a necessidade de estimular o aumento de escolaridade dos moradores, principalmente em áreas técnicas da educação, para que de fato os empregos que estão sendo gerados pelas empresas recém-instaladas possam ser aproveitados pela mão de obra local. Nesse período de transição de uma cidade dormitório para uma cidade industrial que nossa pesquisa se situa tendo como parâmetro a implantação de um conjunto habitacional ${ }^{6}$ que se instala na cidade ofertando moradias populares para cerca de 501 famílias dentro do Programa Minha Casa Minha Vida (PMCMV), sendo um dos primeiros empreendimentos fora do município de Curitiba, ao lado, de Piraquara e Tatuquara.

\section{Metodologia}

A pesquisa ${ }^{7}$ ocorreu sob a interface do diálogo interdisciplinar, a partir da Sociologia com outros campos do conhecimento (Geografia, Economia e Arquitetura). Foram adotados os métodos da pesquisa bibliográfica, documental e qualitativa que permite o estudo dos significados das Políticas

6 Cumpre ressaltar que essa temática foi abordada na minha tese de doutorado defendida em 2014 sob o título de "O conjunto habitacional como solução parcial para relocação de moradias para população de baixa renda: Estudo de caso no município de Fazenda Rio Grande - Região Metropolitana de Curitiba

7 A pesquisa de Pós Doutorado foi desenvolvida durante o ano de 2017 e 2018 sendo realizada em duas etapas: a primeira realizada no 10 Semestre (de janeiro a julho) em que foram realizadas as atividades de planejamento das ações; definição da temática e lócus da pesquisa; levantamento de dados e bibliografia. A segunda, no 20 semestre, de 2017 e 10 semestre de $\mathbf{2 0 1 8}$, onde foram realizadas as atividades de formatação do projeto; ações do trabalho de campo, análise, síntese, balanço crítico e considerações finais.

Rev. Sociologias Plurais, v. 4, número especial 3, p.24-44, nov. 2018 
Públicas, tendo como referencial teórico o trabalho de Minayo ${ }^{8}$, sob a perspectiva marxista, apoiada na historicidade dos processos sociais, na abordagem dialética e no diálogo com a Sociologia compreensiva.

Dessa forma, o sujeito da pesquisa é o beneficiário do Programa Minha Casa Minha Vida, objeto deste estudo, o qual é visto como ator social que atua na sociedade como indivíduo detentor de habilidades e de ação, coletiva e individual, por meio de sua representação social incorporando gestos, reflexões e produzindo conhecimento que dão sentido às suas atitudes e, portanto, não apenas da passividade.

O desenvolvimento da metodologia partiu de uma discussão sobre a visão do morador em relação ao habitar/viver no conjunto habitacional, abrangendo dimensões sociais (condições de vida, equipamentos públicos, acesso a serviços, relações de vizinhança e organização política) e físicas (aspectos físicos da casa). Os aspectos observados relacionam-se com o tema do viver ou morar, em que são avaliados os efeitos de melhoria da qualidade de vida das famílias, com a mudança para o conjunto habitacional.

Podemos distinguir o conceito de casa, moradia e habitação. A ideia de viver no conjunto habitacional vai além do conceito de casa que abrange o aspecto físico construtivo (tamanho e localização) e que tem como função propiciar abrigo e proteção ao indivíduo da ameaça exterior (intempéries, ataque de animais, violência, etc) e de moradia já que esta relaciona-se apenas com os aspectos físicos da casa (janelas, portas, isolamento acústico, etc.). Indo de encontro com o conceito de habitação que é a interação entre a moradia e o mundo exterior:

$8 \quad$ Ver Minayo. 2011, p.23-24. 
(...) uma dimensão que abarca tanto as relações dos moradores de uma casa com seus vizinhos, quanto às relações desses moradores com a sociedade e os equipamentos sociais e de serviços - escolas, creches, postos de saúde, transportes, abastecimento, etc. - que eles utilizam na sua vivência cotidiana (BRASIL, 2014, p.26).

\section{Pesquisa qualitativa}

Sabe-se que em sua origem, trata-se de famílias que vieram de diversas situações de risco e vulnerabilidade social, onde havia a convivência com as enchentes, ocasionando em perda material e doenças, e de outro lado, de ônus habitacional excessivo, comprometendo grande parte de seu salário com o pagamento de aluguel. Para identificar as dimensões subjetivas referentes ao viver no conjunto foram realizadas observações sobre o lugar e entrevistas junto aos moradores, por meio de questionários, em que se procurou compreender aspectos da habitação relacionados ao bem-estar que incorporam aspectos da casa, do seu entorno; equipamentos públicos e serviços, relações de vizinhança e pagamento de taxas. Além disso, procurou-se verificar aspectos da organização política dos moradores, e participação social, resultando em uma análise sobre a cidadania em questão, levando em consideração aspectos do sentimento de pertencimento e de territorialidade, com uma perspectiva avaliativa já que residem naquele lugar desde 2011 (há sete anos).

As perguntas propostas no questionário abrangeram as dimensões da percepção subjetiva com relação à moradia, à habitação e ao bem estar. O questionário foi dividido em quatro partes: (i) dados pessoais; (ii) origem; (iii) condições de vida no Conjunto que abrangem o entorno da moradia (serviços, equipamentos públicos, pagamento de taxas), (iv) relações de vizinhança, organização política e participação social. 
Para cada uma das perguntas propostas o entrevistado foi convidado a responder de forma espontânea, de forma que resultou em uma análise avaliativa com relação à satisfação do indivíduo e sua visão acerca da melhoria de qualidade de vida associada à obtenção da moradia e se existem pontos a melhorar.

A pesquisa resultou na realização de 17 (dezessete) entrevistas com moradores do Conjunto e com representantes do Poder Público, em especifico da Secretaria de Assistência Social. As entrevistas junto às famílias ocorreram no mês de agosto, setembro, e outubro de 2017, e janeiro de 2018.

\section{Aspectos abordados nas entrevistas}

Por meio das entrevistas, observação empírica e reflexão teórica foi possível compreender aspectos do viver das famílias que estão morando no conjunto Jardim Europa. Dos 17 entrevistados, 14 afirmaram que gostam de morar no conjunto e 3 não gostam. Os primeiros são em sua maioria advindos das áreas de risco, o que reforça que as melhorias ocorridas nas condições de vida foram em relação ao fato de terem se transformado em proprietários, ou seja, não precisarem pagar aluguel; na melhoria de sua autoimagem porque agora não são mais vistos como invasores, o que significa que a casa

é deles e ninguém pode tirá-los de lá. Somado ao fato de não sofrerem mais com alagamentos, devido às enchentes, e de terem acesso aos serviços públicos.

A vida na área de risco, segundo os moradores, era de extrema vulnerabilidade, pois moravam na beira do rio e sofriam com alagamentos, perda de materiais e problemas de saúde, e comparada ao fato de se morar no conjunto, era bem pior: 
(A área de risco) Era um bequinho que não entrava caminhão. Não tinha esses serviços que tem no conjunto. (Acervo pessoal)

Com a mudança para o conjunto dispersou-se o medo das enchentes, da perda material e da contaminação por doenças transmissíveis pela água. Além disso, as famílias têm um endereço fixo e a casa agora é própria, ou seja, é um bem patrimonial único que representa estabilidade social e garantia na reprodução da vida e aos herdeiros futuros. Apesar de saírem das áreas de risco, os outros riscos relatados estão relacionados à violência; isolamento do bairro (segregação espacial); baixa mobilidade urbana e trabalho informal.

Outro fato positivo de se morar no conjunto é que não precisam pagar aluguel e que com sua renda pode ser usada para a compra de eletrodomésticos e móveis. Os aspectos relatados reforçam a transformação em suas vidas ocorrida com a mudança para o conjunto, o que resulta no fato dos moradores estarem gostando de morar no conjunto, mesmo existindo situações e demandas ainda não resolvidas pelo Poder Público. Os entrevistados avaliam de forma positiva a mudança em suas vidas:

\footnotetext{
Moro no conjunto há 5 anos. Gosto de morar aqui, porque a casa é minha. Houve melhoria nas condições de vida com a mudança para o conjunto só pelo fato de não ter que pagar aluguel e acesso ao emprego (Acervo pessoal).
}

Entretanto, há a noção de que precisa haver a implantação de melhorias no conjunto e na oferta de atividades destinadas aos jovens.

\footnotetext{
Precisa de mudança. Fazer alguma coisa para os adolescentes. Estão indo para as drogas porque não tem o que fazer. Na faixa de 13 a 18 anos oferecer cursos. Nem todas as mães têm condição de dar uma vida razoável para os filhos. Está a mesma coisa (Acervo pessoal).
}

Os relatos que enfatizam a necessidade de haver no conjunto espaços e ações socioeducativas destinadas às crianças e jovens são em sua maioria 
feita por mães que têm consciência de como essas atividades são importantes e representam uma alternativa para que os jovens não entrem no mundo das drogas. Ao se caminhar pelas ruas do conjunto veem-se adolescentes soltando pipa (meninos) ou sentados na calçada conversando em grupo (meninas).

As políticas públicas de juventude e trabalho, por meio de ações de aumento de escolaridade; capacitação profissional e inserção de jovens e adultos ao mercado de trabalho devem ser urgentemente fortalecidas e integradas às políticas de habitação e assistência social. Aliadas às ferramentas digitais e de comunicação tão em voga na atualidade, as quais os jovens estão antenados, e que devem ser usadas em prol da construção de seus projetos de vida. Por outro lado, há relatos de moradores que demostram que estão insatisfeitos em morar no conjunto, devido à ausência de comércio e serviços próximos; falta de remédios no postos de saúde; qualidade do serviço público ofertado; creche sem funcionamento e situações de violência:

Moro no conjunto há 5 anos. Não gosto de morar aqui. Não tem segurança, saneamento, educação. A escola é ruim. A qualidade de vida piorou com a mudança da área de risco para o conjunto habitacional, pois era área de risco, mas tinha segurança e escola (Acervo pessoal).

Segundo os entrevistados, os equipamentos públicos no bairro (creches, escolas, áreas de lazer) são insuficientes. Foi relatado que houve a construção de uma creche em 2015, mas até hoje a mesma não está funcionando. Segundo o Secretário da Assistência Social do município, José Roberto Zanchi, o funcionamento da creche depende da contratação de novos servidores, e esta ação está prevista para acontecer nos próximos dois anos, devido à falta de recursos da Prefeitura no momento. Foi relatada também a ausência de áreas de lazer para crianças e jovens. O campinho de terra continua a ser um dos únicos espaços de recreação e esporte do 
Conjunto para esse importante segmento social. Outro aspecto a ser melhorado é o transporte público no bairro.

O transporte público é caracterizado por uma única linha que atende o bairro, a cada 45 minutos, de forma lenta e insuficiente: com a mudança para o conjunto os moradores têm que arcar com as taxas (de água, luz e prestação ${ }^{9}$ ). Segundo relatos estão conseguindo pagar as contas, com exceção de famílias que não inscritas na tarifa social. Existe o sentimento positivo de que estão pagando por um bem patrimonial que é seu e que vai continuar na família. Ou seja, será mantido por seus herdeiros. Poucos entrevistados relataram interesse em vender sua casa.

Em relação às relações de vizinhança, a maioria convive entre si, têm boas relações com seus vizinhos próximos, apesar da correria do dia-a-dia. Pelo fato das casas serem geminadas e dividirem a mesma parede, o ambiente favorece o contato e a comunicação entre os vizinhos. As mães vizinhas ajudam "olhando" às crianças e há um ambiente cordial entre elas. Outro aspecto que integra as famílias é a religião evangélica, principalmente. Compartilham crenças e espaços de oração no conjunto nas casas de pregação.

Quanto à prática do associativismo e organização social, a maioria relatou não haver associação de moradores no bairro e, nem lideranças que reivindicam melhorias nas condições de vida das famílias e, portanto, não participam de reuniões dessa natureza. Entretanto, há forte participação religiosa, e frequentam de forma geral, a Igreja evangélica. No conjunto foram identificadas três casas que funcionam como igrejas evangélicas ou templos para cultos.

9 A prestação do imóvel custa cerca de $\mathrm{R} \$ 45,00$ a 90,0o dependendo da renda familiar, representando 5 a $10 \%$ da renda familiar. 
A instalação de um ponto de pregação, como relatam os entrevistados, se faz necessária, pois a Igreja mais próxima era muito longe do conjunto. $\mathrm{O}$ funcionamento desse espaço com cultos semanais aproxima os moradores ajudando em seu enriquecimento espiritual e social, bem como o estabelecimento de parâmetro de conduta moral a ser seguido pelos fiéis:

\footnotetext{
Abrimos o lugar até sair à igreja. Faz três anos e o pastor ainda não conseguiu abrir. As reuniões acontecem uma vez por semana. Cerca de 30 a 40 pessoas participam. O esposo faz a reunião, convida pregador de fora. $\mathrm{O}$ pastor não mora aqui (Acervo pessoal).
}

A igreja representa um local de encontro dos moradores do conjunto onde se pratica a oração para a realização de pedidos e/ou agradecimentos por graças alcançadas; fortalecimento de laços sociais e enfrentamento de momentos difíceis na comunidade tais como com os casos de violência (homicídios em decorrência de tráfico de drogas):

\footnotetext{
A minha oração é para melhorar. Para Deus abençoar nossos vizinhos. Nós temos que nos unir para melhor, para nosso bem. Há 4, 5 meses...houve muitas mortes. O espaço tem ajudado a enfrentar esse momento (Acervo pessoal).
}

Nos últimos três anos pôde-se constatar que houve um incremento na oferta de serviços dentro do conjunto pelos próprios moradores. Seja pela necessidade das familiais acessarem os bens e serviços, como pelo fato dos moradores estarem fora do mercado informal e a abertura dos comércios locais representa uma importante fonte de renda e subsistência das famílias.

Foram abertos nas ruas do conjunto aproximadamente 17 espaços de comércio e serviços, o que retrata a necessidade das famílias a diversos tipos de serviços e de geração de renda. Dessa forma conseguem obter uma renda extra que contribui fortemente para o sustento das famílias. 
Foram identificados os seguintes comércios e/ou serviços:

- Serviços: 3 Igrejas evangélicas; 2 salões de beleza (cabeleireiro e barbearia e estética); 1 costureira; 1 serralheiro e 1 cuidadora de criança.

- Comércios: 2 padarias; 4 mercearias; 2 bares e 1 carro que circula nas ruas do conjunto para vender frutas e verduras.

Perguntados sobre o significado da cidadania e se se consideram um cidadão, os entrevistados responderam que sim, pelo fato de votarem e elegerem seus representantes; por pagarem impostos; pela luta em prol da melhoria das condições de vida das pessoas e de respeitarem as leis.

Sobre o que fariam para melhorar as condições de vida das famílias no conjunto, caso pudessem, foram apontadas inúmeras sugestões, tais como: implantação de áreas de lazer; creche; comércio e serviços; horta comunitária; segurança pública; transporte urbano e mobilidade; ações de geração de renda; capacitação e prevenção às drogas; zoonoses e ações assistencialistas (distribuição de cestas básicas).

Outro aspecto observado é que o bairro Jd. Eucaliptos do qual o conjunto Jardim Europa faz parte está em vias de expansão, com a venda de lotes e casas para construção e implantação e condomínios residenciais, o que indica que nos próximos anos haverá grande circulação de pessoas, veículos e demanda para a instalação de equipamentos urbanos e de serviços a serem implantados na região. Corroborando com a transição da imagem de uma cidade dormitório para uma cidade industrial em desenvolvimento.

A compra e venda de lotes urbanos no bairro e a futura instalação dos condomínios residências reforça a tendência de ocupação dos vazios e as áreas verdes da cidade e especulação financeira, podendo ocasionar o 
deslocamento de pessoas de baixa renda para cidades vizinhas, onde há oferta de terrenos mais baratos, podendo resultar no fenômeno da hiperperiferização que, segundo Haroldo Torres, é a expulsão da população pobre para áreas mais periféricas da cidade, ou para outros municípios.

\section{Considerações finais}

Após sete anos de implantação do conjunto habitacional Jardim Europa verificou-se que a relocação de famílias de baixa renda para conjuntos habitacionais no âmbito do Programa Minha Casa Minha Vida contribui parcialmente para a melhoria das vidas das famílias. Visto que a preocupação maior do Programa é ofertar a casa ao beneficiário, ou seja, remover as famílias de áreas de risco para lugares mais seguros e ambientalmente adequados. Entretanto, poucas iniciativas complementares além da casa são disponibilizadas, pois geralmente os empreendimentos são implantados em bairros periféricos desprovidos de equipamentos públicos adequados, onerando o déficit social existente.

No caso do município de Fazenda Rio Grande, as famílias acabaram utilizando os mesmos equipamentos públicos que tinham acesso antes. A mesma escola ou posto de saúde. $\mathrm{O}$ que mudou mesmo foi que o fato de não serem mais submetida às enchentes e deixaram de pagar aluguel, o que comprometia sua renda.

Em termos de melhorias verifica-se que poucas foram implantadas pelo Poder Público. Não foram instaladas áreas de lazer para as crianças e adolescentes. As ruas do conjunto e o campinho de terra continuam sendo os únicos espaços de lazer. Houve a construção de uma creche, mas a mesma está fechada há dois anos e sem funcionários. Ou seja, ainda existe um longo percurso para a consolidação da cidadania dos moradores (acesso 
e aumento da escolaridade; inserção no mercado formal de trabalho; melhoria da qualidade dos serviços públicos ofertados, maior integração espacial entre o conjunto e à cidade, mobilidade social, entre outros).

A ausência de espaços de lazer e de projetos socioeducativos para o público implica no aumento da incidência de casos de violência, tráfico de drogas e precariedade na qualidade de vida das famílias. Não há um projeto e perspectiva profissional para os jovens a médio e longo prazo.

O que significa dizer que se não houver uma melhoria na escolaridade desse público, possivelmente as gerações presentes reproduzirão ciclos de pobreza e exclusão social, com o advento da criminalidade e gravidez na adolescência.

Os moradores estão gostando de morar no conjunto, principalmente os advindos de áreas de risco, pelo alto grau de vulnerabilidade a que estavam submetidos. Ser proprietário, e não ter que pagar aluguel, representa o principal ganho com a mudança para o conjunto. Isso implica em sua segurança e de sua família e gasto de sua renda com comida e vestuário, fatos que com o pagamento do aluguel eram mais difíceis de ocorrer.

As famílias são sociáveis, conversam e relacionam-se com seus vizinhos próximos de forma cordial. Retratam o compartilhamento de experiências e de cuidado com as crianças. Quando uma vizinha cuida dos filhos da outra até o momento dos pais chegarem em casa.

Um fator de reclamação refere-se ao uso de som alto nos carros pelos jovens, principalmente nos finais de semana. Além disso, há uma unanimidade em relação à necessidade de implantação de melhorias, a serem feitas, principalmente na oferta de comércio próximo e serviços 
públicos (oferta de remédios nos postos de saúde). Além disso, deve ser aperfeiçoado o serviço de transporte público, que é demorado (circulação a cada 45 minutos), sendo atendido por apenas uma linha de ônibus, e piorando aos finais de semana (circulação a cada hora).

Em relação ao associativismo e organização social verifica-se que há uma baixa participação, já que não existem espaços comunitários como associação de moradores e/ou lideranças organizadas. A única organização social que funciona no conjunto, são os pontos de pregação religiosa, que são realizados em parte das casas (espaço improvisado na garagem ou quintal com cadeiras para os fiéis sentarem e uso de caixa de som microfone), a partir de encontros semanais, onde ocorrem cultos, orações e fortalecimento de laços sociais das famílias.

Um aspecto interessante que notamos com a pesquisa realizada em 2017/2018 é o aumento do número de pontos comerciais abertos usando parte das casas do conjunto. Foram identificados 17 espaços comerciais (informais) que oferecem e prestam diversos serviços para os moradores nas seguintes áreas: religiosa; consertos e reformas de roupas; consertos de móveis; estética e alimentação, demonstrando a necessidade do acesso dos moradores a esses serviços já que o comércio formal se localiza em bairros mais distantes do conjunto. O uso múltiplo do imóvel na prestação de serviços de natureza informal de trabalho e de moradia representa uma das únicas fontes de geração de renda das famílias visto que geralmente estão excluídas do mercado formal pelo fato de terem baixa escolaridade e capacitação técnica. Além do fato dos empregos estarem localizados em Curitiba, o que dificulta o seu acesso.

O conjunto habitacional Jardim Europa, do Programa Minha Casa Minha Vida, contribuiu, de forma parcial, com a melhoria das condições de vida 
das famílias que vieram das áreas de risco e da fila do aluguel. As famílias deixaram de ser afetadas pelas enchentes e por problemas de saúde e estão gastando sua renda com alimentação e vestuário. Direitos básicos que estavam distantes no passado. Entretanto, muito ainda tem a conquistar para usufruírem de sua cidadania. Entre as demandas apontadas destaca-se a implantação de áreas de lazer para crianças e jovens; uma rede de comércio e serviços mais próxima do conjunto; creche funcionando e remédios nos postos de saúde. Questões que se colocam como elementos primordiais na visão dos moradores e precisam fazer parte da agenda política do município para que sejam atendidos.

\section{REFERÊNCIAS}

BONDUKI, Nabil. Habitar São Paulo: reflexões sobre a gestão urbana. São Paulo: Estação Liberdade, 2000.

\section{CAIXA ECONÔMICA FEDERAL. O que é o Minha Casa Minha Vida.}

Disponível em versão eletrônica: http://mcmv.caixa.gov.br/minha-casaminha-vida/. Acessado: jun, 2012.

DAVIS, M. Planeta favela. Trad. Beatriz Medina. Ed: Boitempo. São Paulo. 2006.

HARVEY, David et al. A liberdade da cidade. MARICATO, E. Cidades rebeldes: Passe livre e as manifestações que tomaram as ruas do Brasil. São Paulo: Boitempo: Carta Maior, 2013.

IANNI, Octavio. Capitalismo, violência e terrorismo. Rio de Janeiro: Civilização Brasileira, 2004.

.A sociologia e o mundo moderno. Rio de Janeiro: Civilização Brasileira, 2011. 
INSTITUTO BRASILEIRO DE GEOGRAFIA E ESTATÍSTICA (IBGE). Censo Demográfico. 2010. Disponível em versão eletrônica:<http://www.ibge.gov.br/estadosat/perfil.php?sigla=pr>. Acessado em 30/01/2014.

IPARDES. Instituto Paranaense de Desenvolvimento Econômico e Social. Caderno Estatístico Município Fazenda Rio Grande. Janeiro 2018. Disponível em versão eletrônica: http://www.ipardes.gov.br/cadernos/MontaCadPdfi.php?Municipio=83820 \&btOk=ok. Acessado em 31/o1/2018. - Instituto Paranaense de Desenvolvimento Econômico e Social. Caderno Estatístico Município Curitiba. Janeiro 2018. Disponível em versão eletrônica: http://www.ipardes.gov.br/cadernos/MontaCadPdfi.php?Municipio=8oooo \&btOk=ok. Acessado em 31/o1/2018.

KOWARICK. Lucio. Viver em risco: sobre a vulnerabilidade socioeconômica e civil. São Paulo: Ed. 34, 2009.

LULA, Edla. Brasil Econômico (SP): Minha Casa, Minha Vida será ampliado em 2014. Disponível em versão eletrônica em $<$ http://agencia.ipea.gov.br/index.php?option=com_content\&view=article\&i $\mathrm{d}=2$

MARICATO, Ermínia. Brasil, cidades: alternativas para a crise urbana. Petrópolis, RJ: Vozes, 2001.

et al. Cidades rebeldes: Passe livre e as manifestações que tomaram as ruas do Brasil. São Paulo: Boitempo: Carta Maior, 2013. 
MARQUES, Eduardo. TORRES, Haroldo. (Orgs). São Paulo: segregação, pobreza e desigualdades sociais. São Paulo: Editora Senac São Paulo, 2005 .

MARTINS, José de Souza. A sociabilidade do homem simples: cotidiano e história na modernidade anômala. São Paulo: Contexto. 2011. . Exclusão social e a nova desigualdade. São

Paulo: Paulus. 1997.

MINAYO, Maria Cecília de Souza (org.); DESLANDES, Suely Ferreira. Pesquisa social: teoria, método e criatividade. Petrópolis, RJ: Vozes, 2011.

MINISTÉRIO DAS CIDADES. Como produzir moradia bem localizada com os recursos do Programa Minha Casa Minha Vida?: Implementando os instrumentos do Estatuto da Cidade. Cartilha. Brasília. 2010.

.O Ministério. Disponível em versão eletrônica http: <//www.cidades.gov.br/index.php/o-ministerio.html>. Acesso em 01/o7/2012.

PREFEITURA DE FAZENDA RIO GRANDE. Empresas se instalam em Fazenda Rio Grande e devem gerar R\$ 130 milhões em ICMS. Disponível em versão eletrônica http://www.fazendariogrande.pr.gov.br/empresas-se-instalam-em-fazendario-grande-edevem- gerar-r-130-milhoes-em-icms/. Acesso em 31/o1/2018.

RIBEIRO, Corina Alessandra B. Carril. FORTUNATO, Rafaela. MACHADO, Claudia Cristina. Caminhos da sustentabilidade urbana: $O$ desafio da construção da gestão dos riscos socioambientais urbanos. Idéias, n.4, p.244-265, ago./dez. 2012. Unicamp. 
RODRIGUES, Arlete Moysés. A Política Urbana no Governo Lula. Idéias, n.3, p.61-77, ago/dez. 2011. Unicamp.

Moradia nas cidades brasileiras. São Paulo:

Contexto, 2001. Col. Repensando a Geografia.

ROLNIK, R. Planejamento Urbano nos Anos 90: novas perspectivas para velhos temas. In: Luís Ribeiro; Orlando Júnior. (Org.). Globalização, Fragmentação e Reforma Urbana - $O$ futuro das cidades brasileiras na crise. Rio de Janeiro: Civilização Brasileira, 1994.

ROLNIK, R. Apresentação: as vozes das ruas: as revoltas de junho e suas interpretações. In: MARICATO, E. et al. Cidades rebeldes: passe livre e as manifestações que tomaram as ruas do Brasil. São Paulo: Boitempo: Carta Maior, 2013.

MARICATO, E. Cidades rebeldes: Passe livre e as manifestações que tomaram as ruas do Brasil. São Paulo: Boitempo: Carta Maior, 2013.

SANTOS, M. Técnica, espaço, tempo: globalização e meio técnicocientífico, informacional. São Paulo: Hucitec. 1994.

- Por uma outra globalização: do pensamento único à consciência universal. 20 ed. Rio de Janeiro: Record. 2011.

. A urbanização brasileira. São Paulo: Edusp, 2005.

SANTOS, Boaventura de Souza (org.). A Globalização e as Ciências Sociais. 3a.ed. São Paulo: Cortez, 2005.

SASSEN. S. Sociologia da globalização. Ed: Artmed. Porto Alegre, 2010.

SOUZA, M. L. O desafio metropolitano: Um estudo sobre a problemática socioespacial nas metrópoles brasileiras. Rio de Janeiro: Bertrand Brasil, 2000. 
Mudar a cidade: uma introdução crítica ao planejamento e à gestão urbana. za ed. Rio de Janeiro; Bertrand Brasil, 2002.

WACQUANT, Loic. Os condenados da cidade: estudo sobre marginalidade avançada. Rio de janeiro: Revan; FASE, 2001. 